\title{
The Impact of Assessment for Learning on Learner Performance in Life Science
}

\author{
Oluwatoyin Mary Oyinloye ${ }^{1 *}$ (D), Sitwala Namwinji Imenda ${ }^{1}$ \\ ${ }^{1}$ Department of Mathematics, Science and Technology Education, Faculty of Education, University of Zululand, SOUTH AFRICA
}

Received 8 April 2019 - Accepted 22 April 2019

\begin{abstract}
This study investigated the impact of 'assessment for learning' on learner performance in Life Science. Simple random sampling was used to select four schools from the King Cetshwayo District of KwaZulu Natal Province, South Africa, to participate in the study. A quasi-experimental, pretest-posttest comparison group design was used, involving four schools - two forming the 'treatment condition' while the other two served as the 'comparison group'. Altogether, 160 grade eleven learners participated in the study. Two teachers were trained to use assessment for learning (AfL) as an instructional approach, while the two teachers of the comparison group used their usual instructional approaches. Data were analysed using SPSS (V23) and the statistical technique used was the 2-factor ANOVA with repeated measures. The result revealed that learners following an AfL instructional approach performed statistically higher that those following normal classroom instruction. This result is discussed, and recommendations made in respect of both classroom practice and further research. The findings of this study had implications for policy, further research as well as instructional and assessment approaches to be used in the teaching of Life Science in the South African education system.
\end{abstract}

Keywords: assessment for learning, life science, biology, high school, KwaZulu Natal

\section{INTRODUCTION}

Assessment is considered to be one of the main educational tools available to use for different purposes, among which is to maximize learning as well as to motivate students, to improve their performance so that they can meet pre-specified goals and standards. Assessment has assisted teachers over the years to measure learners' achievement through the internal administration of unannounced quizzes, periodic tests and final examinations. Thus, assessments are usually viewed and taken as indicators of school achievement and success, more so than as tools to investigate the cause of success or failure during learning (Shepard, 2000). The conventional assessment approach adopted by most curricula is one where teachers teach and then administer tests and examinations to find out what learners have achieved (summative assessments). This approach leaves the teachers at the centre of the teaching-learning process, where they continue to teach and grade learner performance. This approach tends to ignore and disregard the learning needs of the weaker students who do not possess the capacity to learn at the same pace and timeframes as the others. Consequently, they end up at the bottom of their classes in their schools' grading system or packing order (Chappuis \& Stiggins, 2002).

Assessment has always been an integral part of teaching and learning. It is an important aspect of school life and of a number of stakeholders in education - notably education officials, parents, education institutions at different levels, professional bodies and most importantly, the learners / students (Bennett, 2011). Basically, assessment comprises all activities that teachers and learners carry out to obtain information that can be used to modify teaching and learning, as well as report on learner progress and achievement. These include teachers' observations, discussions in the classroom, and marking / grading learners' work - such as homework and tests (Black \& Wiliam, 1998).

(C) 2019 by the authors; licensee Modestum Ltd., UK. This article is an open access article distributed under the terms and conditions of the Creative Commons Attribution License (http://creativecommons.org/licenses/by/4.0/). \mooyinloye@yahoo.com (*Correspondence) \imendask@yahoo.com 


\section{Contribution of this paper to the literature}

- This study provided an opportunity to examine the effect of the Assessment for Learning (AfL) instructional approach, in the classroom setting, on student learning and performance in Life Science.

- The results revealed that integrating and implementing principles of the AfL instructional approach significantly enhanced learner performance. In addition, the instructional approach not only motivated learners to look forward to the next lesson but also promoted positive relationships between the teachers and their learners.

- This was a ground-breaking empirical investigation in-so-far as this is still an emerging field of study and not much research has been conducted in this area, particularly in developing countries.

Literature has shown that this conventional assessment approach (model) is based on two unpopular principles, namely that in order to promote learning, student anxiety must be stimulated and increased; and that there must be comparison between more successful learners and low performers (achievers), as this will in-turn motivate the low achievers to perform better. This assessment model favours and encourages the fast learners to focus on and value their classroom assessment performance over their learning (Shepard, 2000; Chappuis \& Stiggins, 2002). Although classroom assessment is an essential component of teaching and learning, it should be an on-going process that improves instruction, as opposed to periodic evaluations. Classroom assessment must be modified, in order for it to play a more prominent role in assisting students to learn (Hofstein \& Lunetta, 2004). This could be achieved in by changing its form and content to enhance improvement in learning and promote problem-solving skills (Bennett, 2011; Dunn \& Mulvenon, 2009; Shepard, 2000).

Against this background, curriculum reforms should accommodate the possibility that all students could succeed if some appropriate measures that encourage optimism, confidence and persistence are put in place for all students - irrespective of the category they belong to. Accordingly, all students must be motivated to believe that they can succeed at learning if they make a commensurate effort. Formative assessment is the term used for assessments carried out during learning, tailored towards enhancing students' interests and devotion to learning. Assessment for learning (AFL), which is an application of formative assessment, is a type of assessment which is intended to inform the teaching-learning (instructional) process (Mehmood et al., 2012; Stiggins, 2005a). In recent times, AFL has received a lot of attention as a strategy to improve instruction and learning, as well as motivate students. AFL is continuous, and helps teachers to identify learning needs - as well as inform learners about themselves, and the progress they have made towards attaining intended goals and standards while the learning process is on-going (Stiggins, 2005b).

Duckett (2005) posits that AfL is important because it (a) improves classroom practice, (b) contributes to the personalised learning agenda, whereby learners are empowered to take an active part in their own learning, and (c) develops the confidence of learners to undertake peer and self-assessment. This point is supported by Jones (2005: 1) in her statement that the principal characteristic of AfL "is effective feedback provided by teachers to learners on their progress." In this regard, much rests on (a) the quality of the feedback and how learners receive and ultimately use it. Accordingly, it is Jones' conviction that to effectively implement AfL, teachers "need training and support to enable them to make valuable assessment decisions, to provide quality feedback to learners, and to teach learners to receive feedback positively and use the information contained within it effectively to improve their work" (Jones, 2005: 1). These sentiments have subsequently been echoed by other researchers who have exalted AfL as an effective instructional approach that enhances learner performance (Earl, 2014; Willis, 2011; Van Der Vleuten, Schuwirth, Driessen, Govaerts, \& Heeneman, 2014). Accordingly, Earl (2014) contends that AfL can be a very powerful tool for attaining learning goals, while Willis (2011) reports that students are able to become more self-regulating and autonomous lifelong learners from instructional approaches which encompass the principles of AfL. In particular, Willis contents that this benefit comes from the need, in the implementation of the AfL instructional approach, to share learning goals and assessment criteria with learners - as well as give them experience in self-assessment and guide them with feedback. Moreover, the important thing about AfL is that teachers also benefit from the feedback process in that they are required to pay close attention to what students do and do not understand well. This then places them in a better position to adjust their teaching strategies and pace to meet identified student needs.

\section{STATEMENT OF THE PROBLEM}

Most teachers use assessment as a means of evaluating their learners when instruction has come to an end, usually for the purposes of assigning grades and reporting to parents. Presently, formative assessment in South African schools - including the KwaZulu Natal Province where this study was conducted, does not typically focus on promoting on-going classroom learning (Kanjee \& Moloi, 2014; van Staden \& Motsamai, 2017). This study, therefore, sought to investigate the impact of integrating principles of AfL in classroom instruction and see how 
this would affect learner performance in Life Science - in particular, the topic of 'animal nutrition and cellular respiration'.

\section{RESEARCH OBJECTIVE}

This study sought to investigate the impact of implementing instruction which applies principles of AFL on learner performance in life science.

\section{RESEARCH HYPOTHESIS}

More specifically, this study set out to test the following null hypothesis:

$\underline{H}_{0}:$ There will be no statistical difference in the performance of learners following an AFL instructional approach compared to those following normal classroom instruction.

The alternative hypothesis was:

$\underline{\mathrm{H}_{\mathrm{i}}}$ : Learners following an AFL instructional approach will perform statistically higher that those following normal classroom instruction.

\section{METHODOLOGY}

This study was conducted in the King Cetshwayo District of KwaZulu Natal Province, South Africa, using a pre-and-post-test, quasi-experimental non-equivalent comparison-group research design. Random assignment of subjects/participants to experimental groups is a very important feature of experimental designs because it is through this process that all groups can be said to be equivalent at the beginning of an experiment. However, for practical reasons, this study used preexisting intact classes, therefore only qualifying to be referred to as a quasiexperimental design. In line with his design, both groups were pre-tested on the dependent variable, followed by the treatment being administered to one of the groups, and then both groups were post-tested on the dependent variable. The purpose of the pre-test was to detect initial differences, if any, between the treatment and comparison groups so that differences observed after the treatment would reasonably be attributable to the impact of the treatment.

\section{Instrumentation}

A written test was used to gather information to ascertain what impact, if any, the AfL approach had on learner performance. The test was constructed by the four participating teachers, in collaboration with the first author. Subsequently, the test was validated by two university biology education experts and one subject specialist employed by the Department of Education as a subject advisor. The validation of the test focused on its content and face validity. The reliability of the test was Cronbach's alpha $=0.65$ (determined from the pre-test in the main study), and this met the criteria for a reliable test (Neuman, 2011). The same test was administered to all the learners in the usual way as a class test, before and after the instructional interventions.

\section{Data Analysis}

The data were analysed using SPSS (V23) and the graphs were constructed using MS Excel (2013). The statistical technique used was the 2-factor ANOVA with repeated measures, at the 95\% confidence level.

\section{Target Population and Research Sample}

The target population comprised all grade eleven learners enrolled for Life Science in the district. However, the accessible population were learners from Empangeni and Richard Bay wards. Simple random sampling was used to select four schools that participated in the study: two schools constituted the treatment condition while the other two served as the comparison group. Altogether, one hundred and sixty (160) learners participated in the study made up of forty learners per class.

\section{The Classroom Intervention}

As an impact study, it is important to give a bit more information about what constituted the 'treatment condition' or classroom intervention in order to describe what was hypothesized to impact learner performance. The treatment condition was designed by the first author in collaboration with the teachers of the four participating schools. The instruction constituting the 'treatment condition' was based on the five key strategies of AFL presented in Table 1 (Wiliam \& Thompson (2007: 7). 
Table 1. The five key strategies of assessment for learning

\begin{tabular}{|c|c|c|c|}
\hline & Where the learner is going & Where the learner is right now & How to get there \\
\hline Teacher & $\begin{array}{l}\text { 1. Clarifying learning intentions } \\
\text { and criteria for success }\end{array}$ & $\begin{array}{l}\text { 2. Engineering effective class-room } \\
\text { discussions, questions, and learning } \\
\text { tasks that elicit evidence of learning }\end{array}$ & $\begin{array}{l}\text { 3. Providing feedback that } \\
\text { moves learners forward }\end{array}$ \\
\hline Peer & $\begin{array}{l}\text { Understanding learning } \\
\text { intentions and criteria for success }\end{array}$ & $\begin{array}{l}\text { 4. Activating students as instructional } \\
\text { resources for one another }\end{array}$ & \\
\hline Learner & $\begin{array}{l}\text { Understanding learning } \\
\text { intentions and criteria for success }\end{array}$ & 5. Activating students as the owners of & heir own learning \\
\hline
\end{tabular}

[Source: Black \& Wiliam, 2009: 5]

Table 2. Comparison of means before implementation of treatment $(n=160)$

\begin{tabular}{ccccccccc}
\hline Group & Mean & Range & SE & $\begin{array}{c}\text { Lower } \\
\text { Bound }\end{array}$ & $\begin{array}{c}\text { Upper } \\
\text { Bound }\end{array}$ & to & P-Value & Result \\
\hline Comparison & 11.21 & $24-3=21$ & 0.5 & 10.2 & 12.1 & 0.36 & $>0.05$ & Not Sig \\
\hline Treatment & 10.9 & $28-3=25$ & 0.5 & 9.9 & 11.9 & & & \\
\hline
\end{tabular}

Making goals and assessment criteria understood by learners is one of the hallmarks of the AfL instructional process. Goal setting with learners and explaining success criteria engages learners in the instructional process by establishing clear expectations for them to be successful in attaining lesson learning outcomes. Learners need to understand and know the learning target/goal and criteria for reaching the goal. Thus, all the lessons for the treatment group started with a segment where the learning intentions and success criteria were stated, explained and clarified. The second stage involved getting into the subject matter content through different learning and teaching strategies, including question-answers, discussions, supervised classwork, and other interactive approaches which allowed for getting and giving and getting of feedback to and from the learners. The last two classroom activities entailed having the learners themselves assist one another to understand the instruction as well as giving feedback to each other on the learning tasks and taking responsibility for their learning.

One assessment instrument that has received a lot of attention lately as a tool to assist both the teacher and learners see where they are going is the 'scoring rubric'. The rubric is an assessment instrument that contains assessment criteria as well as espoused standards, specifying levels of attainment for each criterion (Jonsson, 2008; Reddy \& Andrade, 2010). Like anything that is new, this means that both teachers and learners need to be trained in the use of scoring rubrics so that the purpose of their use is clear to both. To be an effective too that yields desired results, rubrics need to be applied purposefully and carefully. So, the teachers and learners established and defined quality work together; thus, learners participated in establishing acceptable behaviours for the class, as well as in determining what needed to be included in the criteria for success. Using learners' work or exemplars of what was expected helped learners to understand where they needed to be and the most effective process for getting there. Thus, scoring rubrics were introduced to the two classes and learners were asked to assess their answers against the levels of quality for each criterion on the rubric - and for each criterion that was discussed, the teachers asked the learners to justify their judgements.

Overall, these key strategies revolve around the three elements of (a) where the learner is going, (b) where the learner is right now, and (c) how to get the learner there. The study was conducted over a six-week period involving the topic 'animal nutrition and cellular respiration.' There were three one-hour lessons per week and all the learners studied this topic over the period of the six weeks. For the comparison group, the teachers were asked to teach according to the normal way they taught the subject, while the treatment group received instruction according to the strategy described in Table 1.

\section{RESULT AND FINDING}

The study sought to find out the effect of an AfL instructional approach on learners' performance. The results are presented below under the various sub-headings.

\section{Test of Initial Equivalence}

Given that that intact classrooms were used, instead of random assignment of participants to the Comparison and Treatment conditions, it was important to establish the equivalence of the two groups before the administration of the respective instructional interventions. This was done in order to satisfy the assumption of homoscedasticity, which is central to pre-post experimental designs. The results of the statistical comparison used to establish the equivalence of the Comparison vis-a-vis the Treatment group are presented in Table 2. 


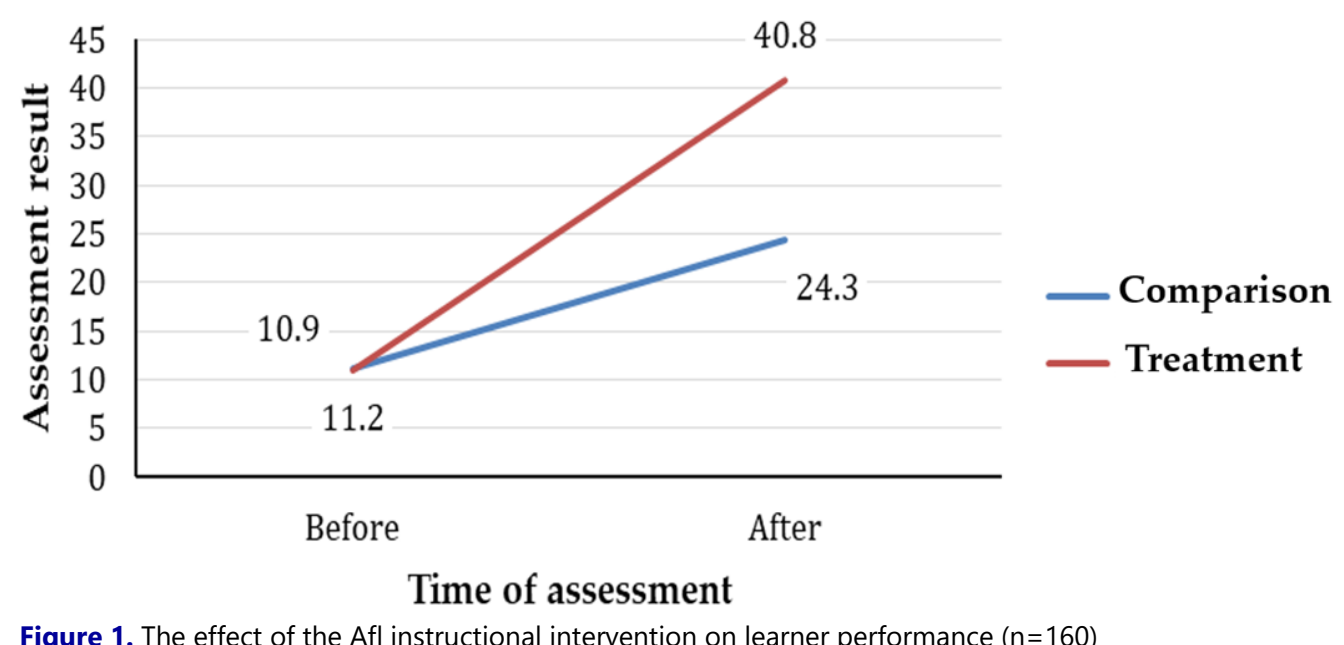

Figure 1. The effect of the Afl instructional intervention on learner performance $(n=160)$

Table 3. Gains made by learners between pre- and post-tests $(n=160)$

\begin{tabular}{cccccc}
\hline Experimental Condition & Pre-test & Pre-test & SD & to & Result \\
\hline Comparison Group & 11.2 & 24.3 & 5.54 & -15.69 & Significant \\
\hline Treatment & 10.9 & 40.76 & 7.55 & & \\
\hline
\end{tabular}

Table 4. Comparison of means after implementation of treatment $(n=160)$

\begin{tabular}{ccccccccc}
\hline Group & Mean & Range & SE & $\begin{array}{c}\text { Lower } \\
\text { Bound }\end{array}$ & $\begin{array}{c}\text { Upper } \\
\text { Bound }\end{array}$ & $\mathbf{t}_{\mathbf{0}}$ & P-Value & Result \\
\hline Comparison & 24.3 & $40-9=31$ & 0.7 & 22.9 & 25.8 & -15.69 & $>0.05$ & Significant \\
\hline Treatment & 40.8 & $65-26=39$ & 0.7 & 39.3 & 42.2 & & & \\
\hline
\end{tabular}

Table 5. The 2-factor ANOVA confirmatory test

\begin{tabular}{cccc}
\hline & p-value & Partial Eta Square & Observed Power \\
\hline Time * Group & $<0.05$ & 0.509 & 1.000 \\
\hline
\end{tabular}

The results in Table 2 show that the two groups were statistically equivalent before the onset of the interventions. It was important to establish this in order to ensure that differences in learner performance between the two groups that may be observed after the implementation of the intervention would reasonably be attributed to the treatment and not to some pre-existing characteristics within the research sample.

\section{Testing the Impact of the Interventions}

Figure 1 presents the results of both the treatment and comparison groups after the six-week instructional interventions.

According to Figure 1, the treatment group performed much higher (40.8\% mean score on the post-test) than the comparison group $(24.3 \%)$. Compared to their respective baseline scores, both groups made notable gains. However, the treatment group scored much higher than the comparison group - almost twice better. This information is also presented in Table 3, which shows that although both groups started from the same baseline, they ended far apart after the two interventions - in favour of the one that followed the AfL instructional approach.

However, each group made statistically significant gains from its baseline. Thus, it may be said that the two groups benefited from their respective instructional processes.

In Table 4 the two post-test means of the two experimental conditions are compared to establish whether or not the observed differences between them are statistically significant.

The statistical comparison in Table 4 was a test of the statistical hypothesis of this study. On the basis of the result in Table 4, the null hypothesis is rejected in favour of its alternative, namely that learners following an AFL instructional approach performed statistically higher that those following normal classroom instruction. Therefore, on the basis of this result, it may be concluded that the AfL instructional approach is much more effective than the normal instruction. Table 5 displays the results of a 2-factor ANOVA performed on the data as a confirmation of the result displayed in Table 4. 
Table 6. The effectiveness of the AfL approach $(n=160)$

\begin{tabular}{cccc}
\hline Time & Comparison & Means & p-value \\
\hline Before & Treatment - Comparison & 10.9 vs 11.2 & $>0.05$ \\
\hline After & Treatment - Comparison & 40.8 vs 24.3 & $<0.05$ \\
\hline
\end{tabular}

In this comparison, 'Time * Group' refers to the interaction between Time and Group. The p-value is less than 0.05 , which confirms the presence of a statistically significant interaction, indicating that the Group profiles are not parallel. The 'Partial Eta Square' measures the effect size. In this case, the effect size of 0.509 is greater than the threshold Eta value of approximately 0.25, implying that the observed difference between the treatment and comparison groups is practically significant over time. The 'Observed Power' of the test is 1.000 (the largest it can ever be), which means that the test yielded a strong (reliable) result. The null hypothesis is rejected; the alternate hypothesis is accepted. Therefore, there has been a significant difference in performance between learners following the AfL instructional approach in comparison to those following normal instruction.

To summarise, Table 6 shows that the pre-test comparison of means yielded a statistically non-significant result, proving homoscedasticity; while the post-test comparison yielded a statistically significant result, showing that the treatment condition was much more effective than normal instruction. It shows that the pre-test comparison of means yielded a statistically non-significant result, proving homoscedasticity; while the post-test comparison yielded a statistically significant result, showing that the treatment condition was much more effective than normal instruction.

\section{DISCUSSION}

The result of this study has revealed that learners following the AfL instructional approach performed significantly higher than their counterparts in the comparison group who received normal instruction. The significant impact of the AfL instructional approach seen in this study can be attributed to the efforts and hard work of the two teachers who tried very hard to implement the AfL strategies with their learners. This involved making significant changes in the way they were accustomed to teaching, and for the learners in the way they were accustomed to learning. However, the fruits of the teachers' willingness to try out something different, and the learners' ability to first tolerate and subsequently embrace the new way to learn, became evident in the performance of the learners. Their collective efforts yielded significant learning gains far above the performance level of learners who received normal instruction.

This achievement should be seen in the light of the five attributes of the AFL strategy which was applied in respect of the group that was exposed to the treatment condition. The strategy necessitated a change in classroom assessment practices incorporating the five elements of Afl, namely making goals and assessment criteria explicit and understandable, creating a situation that made learning visible, providing feedback that moved learners forward, activating learners as resources to each other, and activating learners as owners of their learning (Wiliam \& Thompson, 2007). The other elements associated with this instructional approach, such as the use of the right formative assessment tools during instruction, the scoring rubric, self-assessment, peer assessment and peer feedback - all contributed in making the learners learn better.

In literature, similar findings have been recorded by Ehrenberg, et al. (2001), who reported the impact of formative assessment on student achievement to be four to five times greater than the effect of reducing class size. Furthermore, the findings of this study are consistent with those reported by other researchers (Condie, et al., 2005; DfES, 2007; Hayward \& Spencer, 2010; Kellard et al., 2008; Kirton et al., 2007; Ofsted, 2008; Webb \& Jones, 2009). These authors generally ascribe these positive results to the implementation of AfL which, by its very nature, encourages the teacher and learners to understand clearly what is to be learnt, how to get there and the evidence of having arrived at the desired destination. For instance, one study conducted by Kirton (2007) reported that $78 \%$ of participants evaluated the intervention as successful in its impact on primary school pupils' attainment of intended learning outcomes, while two participating schools also reported improvements in summative tests as a result of AfL strategies. Similarly, another study conducted by DfES (2007) noted complete or incomplete improvements in learner attainment in eight schools involved in an AfL project in terms of secondary school learners (DfES, 2007).

Most of these studies were conducted in school settings quite different from those obtaining in African countries. Thus, it is gratifying that similar results could be recorded in an African setting. It may be said, therefore, that the model used in this study to apply AFL has been quite effective. Nonetheless, it is important to note that the transition from what has been termed 'normal' instruction in this study, to implementing a strategy that integrated AFL, was not easy. Both learners and teachers had to make an extra effort to understand what this approach expected of them. However, once they got used to the approach, both teaching and learning appeared to be pleasant, fruitful and purposeful. 


\section{CONCLUSION AND RECOMMENDATIONS}

The results of this study suggest that AfL holds a lot of promise for effective teaching and learning. This approach does not require any extra tools or equipment to those already available to most teachers. What is needed is mainly a recognition of the importance of making both learning intentions and learning outcomes clear to learners, getting and giving appropriate feedback on the learning activities, having learners assist each other and making them own the learning process. Therefore, the authors wish to encourage teachers to embrace the principles of AFL, as articulated in the model used in this study and elsewhere, and implement AFL strategies in their classrooms. A similar recommendation goes to curriculum designers and subject advisors to consider the AFL strategies very seriously so that a systemic change can occur within the school system as a whole towards a better understanding of formative assessment, generally, and AFL in particular. The authors are convinced that the efforts that schools will make to embrace a better use of formative assessment, including AFL, will be justified by subsequent learner achievements. Finally, as far as the researchers are aware, at the time of this study, there were no other similar studies already carried out in South Africa - and perhaps very few in Africa as a whole. Accordingly, it appears justified to recommend further research on the effectiveness of a formative-assessmentbased approach to teaching, where assessment is used to promote learning within the course of a lesson. Certainly, this way of integrating assessment with learning is a good way to teach and learn. Indeed, in this study, the AFL approach also appeared to have, not only motivated learners to look forward to the lessons, but also promoted positive relationships between the teachers and their learners. No proper learning can take place where teacherlearner relationships are poor or unfavourable.

\section{ACKNOWLEDGEMENT}

The study reported in this manuscript was supported by the University of Zululand through funding received from the University Research Committee (UZREC 171110-030 PGD 2016/118).

\section{REFERENCES}

Bennett, R. E. (2011). Formative assessment: A critical review. Assessment in Education: Principles. Policy and Practice, 18(1), 5-25. https:/ / doi.org/10.1080/0969594X.2010.513678

Black, P., \& Wiliam, D. (1998). Assessment and classroom learning. Assessment in Education, 5(1), 7-74. https://doi.org/10.1080/0969595980050102

Black, P., \& Wiliam, D. (2009). Developing the theory of formative assessment. Educational Assessment. Evaluation and Accountability, 21(1), 5-31. https://doi.org/10.1007/s11092-008-9068-5

Chappuis, S., \& Stiggins, R. J. (2002). Classroom assessment for learning. Educational Leadership, 60(1), 40-44.

Condie, R., Livingston, K., \& Seagraves, L. (2005). Evaluation of the assessment for learning programme: Final report. Glasgow: Quality in Education Center, University of Strathclyde.

DfES (Department for Education) (2007). Assessment for learning: Eight schools project report. London: DfES Publications.

Duckett, I. (2005). Foreword. In Jones, C.A. Assessment for Learning. Vocational Learning Support Programme: 16-19, London, Learning and Skills Development Agency.

Dunn, K. E., \& Mulvenon, S. W. (2009). A critical review of research on formative assessment: The limited scientific evidence of the impact of formative assessment in education. Practical Assessment, Research and Evaluation, 14(7), 1-11.

Earl, L. M. (2014). Assessment as Learning: Using Classroom Assessment to Maximize Student Learning (2nd ed.), Cheltenham (Australia), Hawker Brownlow Education.

Hayward, L., \& Spencer, E. (2010). The complexities of change: Formative assessment in Scotland. Curriculum Journal, 21(2), 161-177. https:/ / doi.org/10.1080/09585176.2010.480827

Hofstein, A., \& Lunetta, V.N. (2004). The laboratory in science education: Foundations for the twenty-first century. Science education, 88(1), 28-54. https:/ / doi.org/10.1002/ sce.10106

Kanjee, A., \& Moloi, Q. (2014). South African teachers' use of national assessment data. South African Journal of Childhood Education, 4(2), 90-113. https:/ / doi.org/10.4102/ sajce.v4i2.206

Kellard, K., Costello, M., Godfrey, D., Griffiths, E., \& Rees, C. (2008). Evaluation of the developing thinking and assessment for learning development programme. Cardiff: Welsh Assembly Government. 
Kirton, A., Hallam, S., Peffers, J. Robertson, P., \& Stobart, G. (2007) Revolution, evolution or a Trojan horse? Piloting assessment for learning in some Scottish primary schools. British Educational Research Journal, 33(4), 605-627. https:/ / doi.org/10.1080/01411920701434136

Mehmood, T., Hussain, T., Khalid, M., \& Azam, R. (2012). Impact of Formative Assessment on Academic Achievement of Secondary School Students. International Journal of Business and Social Science, 3(17), 101-104.

Neuman, W. L (2011). Social research methods: Qualitative and Quantitative Approaches, Sixth Edition, University of Wisconsin, Whitewater.

OFSTED. (2008). Assessment for learning: The impact of National Strategy support. London: Office for Standards in Education

Shepard, L. A. (2000). The role of assessment in a learning culture. Educational Researcher, 29(7), 4-14. https://doi.org/10.3102/0013189X029007004

Stiggins, R. (2005a). Assessment for learning defined. Retrieved on April 2, 2015 from http:/ / ati.pearson.com/downloads/AfLdefined.pdf

Stiggins, R. (2005b). From formative assessment to assessment for learning: A path to success in standards-based schools. Phi Delta Kappan, 87(4), 324-328. https:/ / doi.org/10.1177/003172170508700414

Van Der Vleuten, C. P. M., Schuwirth, L. W. T., Driessen, E. W., Govaerts, M. J. B., \& Heeneman, S. (2015). Twelve Tips for programmatic assessment. Medical Teacher, 37(7), 641-646. https:/ / doi.org/10.3109/0142159X.2014.973388

Van Staden, S., \& Motsamai, P. (2017). Differences in the quality of school-based assessment: Evidence in Grade 9 mathematics achievement. Pythagoras, 38(1), 1-10. https:// doi.org/10.4102/ pythagoras.v38i1.367

Webb, M., \& Jones, J. (2009). Exploring tensions in developing assessment for learning: Assessment in Education, 16(2), 165-184. https:/ / doi.org/10.1080/09695940903075925

Wiliam, D., \& Thompson, M (2007). Integrating assessment with learning: What will it take to make it work? In Carol A. Dwyer (Ed), The future of assessment (pp.53-82). New York, NY: Routledge. https:/ / doi.org/10.4324/9781315086545-3

Willis, J. (2011). Affiliation, autonomy and assessment for learning. Assessment in Education: Principles, Policy $\mathcal{E}$ Practice, 18(4), 399-415. https:/ / doi.org/10.1080/0969594X.2011.604305

\section{http://www.ejmste.com}

